\title{
Physicians'knowledge, attitude and practice towards erectile dysfunction in Saudi Arabia
}

\author{
M.F. Abdulmohsen, ${ }^{1}$ I.S. Abdulrahman, ${ }^{1}$ A.H. Al-Khadra, ${ }^{1}$ A.A. Bahnassy, ${ }^{2}$ S.A. Taha,${ }^{3}$
} B.A. Kamal ${ }^{3}$, A.M. Al-Rubaish ${ }^{1}$ and A.H. Al-Elq

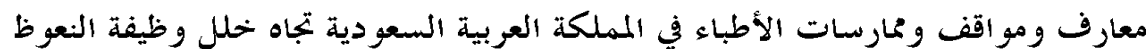

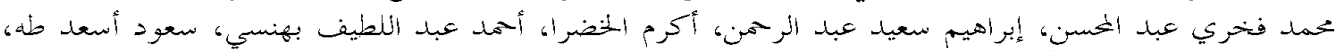

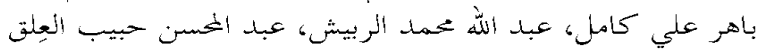

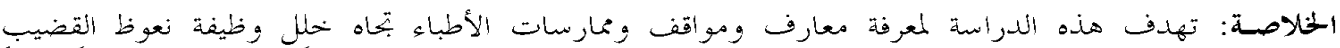

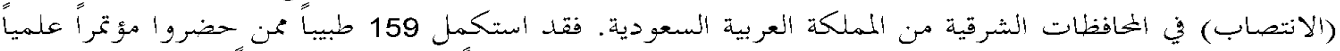

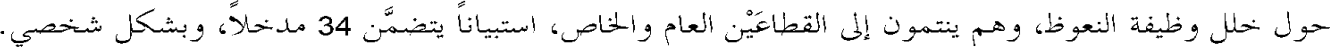

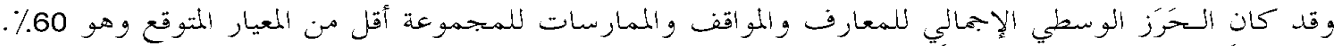

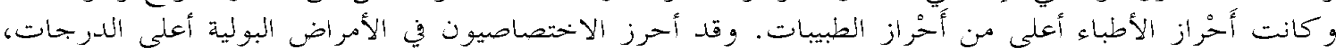

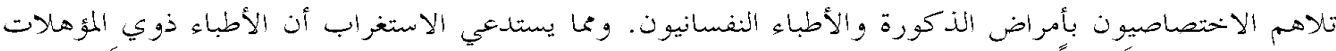

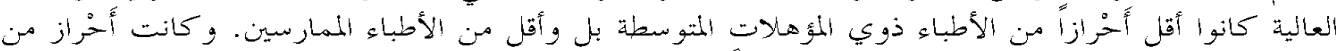

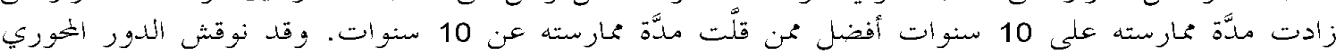

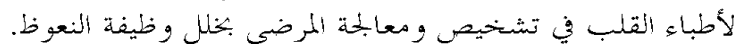

ABSTRACT We aimed to test the knowledge, attitude and practice (KAP) of physicians towards erectile dysfunction in the Eastern province of Saudi Arabia. At a scientific meeting about erectile dysfunction, 159 physicians from both government and private sectors answered a 34-item questionnaire in private. The mean total KAP score for the group was below the expected standard of $60 \%$. Male physicians scored significantly higher than females. Urologists scored the highest, followed by andrologists. Surprisingly, physicians with higher qualifications scored lower than those with intermediate qualifications and even less than general practitioners. Those who had practised for $\geq 10$ years scored better than those with $<10$ years practice. The role of cardiologists in the diagnosis and management of erectile dysfunction is discussed.

Connaissances, attitudes et pratiques des médecins concernant le dysfonctionnement érectile en Arabie saoudite

RÉSUMÉ Cette étude visait à tester les connaissances, attitudes et pratiques (CAP) des médecins concernant le dysfonctionnement érectile dans la province orientale d'Arabie saoudite. Lors d'une réunion scientifique sur le dysfonctionnement érectile, 159 médecins du secteur gouvernemental et du secteur privé ont répondu en privé à un questionnaire de 34 items. Le score CAP total moyen pour le groupe était en deçà du niveau escompté de $60 \%$. Les médecins hommes ont obtenu un score significativement plus élevé que les médecins femmes. Les urologues ont eu les scores les plus élevés, suivis par les andrologues. De manière surprenante, les médecins ayant les qualifications les plus élevées ont eu des scores inférieurs à ceux qui avaient des qualifications intermédiaires et même à ceux des généralistes. Les médecins qui pratiquaient depuis 10 ans ou plus ont eu de meilleurs scores que ceux qui pratiquaient depuis moins de 10 ans. Le rôle joué par les cardiologues dans le diagnostic et la prise en charge du dysfonctionnement érectile est examiné.

${ }^{1}$ Department of Internal Medicine; ${ }^{2}$ Department of Family and Community Medicine; ${ }^{3}$ Department of Urology, College of Medicine, King Faisal University, Dammam, Saudi Arabia.

Received: 06/05/03; accepted: 19/11/03

بلملة الصحية لشرق المتوسط، منظمة الصحة العلمية، المجلد العاشر، العلددان ع-0، ع • • 


\section{Introduction}

Erectile dysfunction is one of the more commonly under-diagnosed medical disorders in the world [1]. It is defined as the persistent inability to maintain or to achieve an erection of sufficient rigidity to have satisfying sexual activity [2]. Recent estimates from the National Institutes of Health (NIH) in the United States suggest that about 30 million Americans have partial or complete erectile dysfunction [1].

The problem of erectile dysfunction is mainly linked to age, as shown in the Massachusetts Male Aging Study, where 52\% of the male study population aged 40-70 years had some degree of erectile dysfunction [3]. Surprisingly, only about 1 in 10 men with erectile dysfunction between 18 and 59 years of age seek medical advice about their problem [4]. In another study, $44 \%$ of 500 patients who were consulting their urologists for reasons other than erectile dysfunction were found to have a history of erectile dysfunction but failed to inform their physicians about their problem. The reason given by $74 \%$ of them was embarrassment [5].

It is believed that there are 2 major reasons for overlooking erectile dysfunction as a major health disorder. First, the majority of men with erectile dysfunction do not seek medical advice despite the growing awareness of the available treatment options. The main causes for that are: social as well as religious; concerns about embarrassment and shame; indifference; and fears about side-effects of treatment. Secondly, the majority of physicians do not ask enough questions to identify men with erectile dysfunction or encourage them to seek treatment [6].

The prevalence of erectile dysfunction in non-insulin dependent Saudi diabetic men from the Mecca region was $81.1 \%$
[7]. The risk factors for erectile dysfunction were: age, history of long standing diabetes for more than 10 years, and poor metabolic control. In another study including 388 patients with different degrees of erectile dysfunction from Jeddah, Saudi Arabia, the severity of erectile dysfunction was mainly age-related, and physical inactivity, alcohol consumption and drug addiction were the only independent risk factors after adjusting for age. It has also been found that severe erectile dysfunction was a strong predictor of poor quality of life [8]. Therefore, physicians in general, and cardiologists in particular, should take the initiative to open the discussion about sexual activity with their male patients for several important reasons. First, erectile dysfunction and coronary artery disease share many risk factors such as diabetes mellitus, hypertension, smoking, dyslipidaemia and ageing. Secondly, it is possible that the same vascular and endothelial changes that take place in the coronary arteries are likely to occur in the cavernosal arteries that supply the penile erectile tissue $[2,3,9]$. The evaluation of erectile function of a male patient may thus open a clinical window to a silent, yet growing coronary, peripheral or cerebrovascular disease and to other undiagnosed medical problems such as hypertension, diabetes mellitus and dyslipidaemia [10-16]. One more aspect of the problem of overlooking erectile dysfunction in our opinion is the inappropriate knowledge, attitude and practice (KAP) of physicians towards erectile dysfunction, which may alter their ability to provide their patients with proper advice about the treatment options.

The objective of this study was to assess the KAP of practising physicians towards erectile dysfunction in one region of Saudi Arabia.

لبحلة الصحية لشرق المثتوسط، منظمة الصحة العلمية، البحلد العاشر، العدذان ع-0، ع • • 


\section{Methods}

\section{Sample}

This was a cross-sectional study carried out in the Eastern province of Saudi Arabia. The estimated sample size was 200 physicians, selected from both the government and private medical sectors in Dammam region (Dammam, Al-Qatif and Al-Khobar). A multistage random sample was used, where physicians were classified into 2 main strata: government and private. Using proportional allocation, a systematic random sample was used to select the required number of physicians from each stratum.

\section{Questionnaire}

A questionnaire with 36 questions was designed to collect information on: demographic and professional data of the recruited physicians (8 items), current knowledge (13 items), attitudes towards erectile dysfunction (8 items) and practices when dealing with a patient suffering from erectile dysfunction (7 items).

The questionnaire was designed by the authors and validated by a panel of experts in the field. A pilot study was undertaken on 20 physicians from the university hospital who were excluded from the study population before choosing the sample. Based on the results of the pilot study, the questionnaire was modified. The weighting of each question relating to knowledge, attitude and practice was determined by the research team and experts in epidemiological studies. The total score was 100 marks and the maximum scores for knowledge, attitude and practice questions were 42, 28 and 30 marks respectively.

\section{Data collection and analysis}

The targeted physicians were invited to attend a scientific meeting on erectile dysfunction at 2 different locations, one for the private and the other for the government hospital doctors.

The questionnaires were distributed and answered in a 45-minute private session at the beginning of the scientific meeting. The second part of that scientific meeting was a comprehensive lecture about erectile dysfunction including anatomy and pathophysiology, delivered by the principal investigator.

The data were entered into the personal computer using SPSS, version 10. Descriptive statistics for all variables were performed after scrutinizing the data. Statistical analysis was made using $t$-test, Mann-Whitney test, analysis of variance and Kruskal-Wallis as appropriate.

\section{Results}

Two hundred (200) physicians were invited to attend the 2 scientific meetings. A total of 192 physicians were able to attend (96\%) and out of that number, 159 answered the questionnaire, giving a response rate of $82.8 \%$. The number of male physicians was much higher than female physicians: 151 (95.6\%) and 7 (4.4\%) respectively. One physician failed to mention his/ her sex.

The mean and standard deviation (SD) overall KAP score for all the respondents was 55.6 (14.9) (maximum 100), the knowledge score was 19.0 (8.2) (maximum 42), the attitude score was 19.0 (4.5) (maximum 28) and the practice score was 17.3 (5.3) (maximum 30).

Table 1 shows the mean total KAP score by sex. The mean overall KAP score for females was significantly lower than that of male physicians $(P<0.001)$. This was reflected in significantly lower mean knowledge and practice scores for females $(P=$ 0.021 and $P=0.011$ respectively). The

بلملة الصحية لشرة المتو سط، منظمة الصحة العالمية، البحلد العاشر، العلددان ع-0، ع • • 


\begin{tabular}{|c|c|c|c|c|c|}
\hline \multirow[t]{2}{*}{ Variable } & \multirow[t]{2}{*}{ No. } & \multicolumn{4}{|c|}{ Mean (SD) } \\
\hline & & $\begin{array}{c}\text { Knowledge } \\
\text { (max. 42) }\end{array}$ & $\begin{array}{l}\text { Attitude } \\
\text { (max. 28) }\end{array}$ & $\begin{array}{l}\text { Practice } \\
\text { (max.30) }\end{array}$ & $\begin{array}{c}\text { Total } \\
\text { (max. 100) }\end{array}$ \\
\hline \multicolumn{6}{|l|}{ Sex } \\
\hline Male & 151 & $19.4(8.1)$ & $19.0(4.5)$ & $17.6(5.2)$ & $58.2(14.9)$ \\
\hline \multirow[t]{2}{*}{ Female } & 7 & $11.4(5.6)$ & $17.4(3.4)$ & $12.5(3.9)$ & $42.9(9.6)$ \\
\hline & & $P=0.011$ & $P=0.353$ & $P=0.013$ & $P=0.021$ \\
\hline \multicolumn{6}{|l|}{ Specialty } \\
\hline Urologist & 14 & $29.0(6.2)$ & $19.7(4.5)$ & $23.6(2.9)$ & $73.0(8.9)$ \\
\hline Andrologist & 11 & $24.3(10.6)$ & $21.1(4.0)$ & $21.6(3.8)$ & $67.0(14.9)$ \\
\hline Psychiatrist & 7 & $20.0(7.3)$ & $20.9(6.6)$ & $19.3(3.5)$ & $60.1(14.1)$ \\
\hline General surgeon & 16 & 20.7 (8.2) & $20.8(3.4)$ & $16.9(5.6)$ & $58.9(15.9)$ \\
\hline Cardiologist & 10 & $20.4(8.9)$ & $18.6(4.9)$ & $18.3(6.1)$ & $57.3(18.1)$ \\
\hline Gynaecologist & 6 & $19.7(9.9)$ & $21.5(3.6)$ & $13.2(6.7)$ & $54.4(19.2)$ \\
\hline \multirow[t]{2}{*}{ Other specialty } & 84 & $16.9(6.5)$ & $18.3(4.2)$ & $16.3(4.6)$ & $51.8(11.8)$ \\
\hline & & $P<0.001$ & $P=0.087$ & $P<0.001$ & $P<0.001$ \\
\hline \multicolumn{6}{|l|}{ Qualifications } \\
\hline MD or equivalent & 31 & $14.5(6.3)$ & $17.1(4.6)$ & $15.0(4.3)$ & $47.4(11.7)$ \\
\hline MSc or equivalent & 55 & $21.0(8.9)$ & $20.1(3.9)$ & $18.3(5.2)$ & $59.5(15.3)$ \\
\hline \multirow[t]{2}{*}{ GP with MB BS } & 66 & $19.9(7.7)$ & $19.4(4.4)$ & $18.1(5.3)$ & $57.5(14.2)$ \\
\hline & & $P<0.001$ & $P=0.007$ & $P=0.008$ & $P<0.001$ \\
\hline \multicolumn{6}{|l|}{ Years of practice } \\
\hline$<10$ & 52 & $17.3(6.8)$ & $18.3(4.0)$ & $15.9(4.6)$ & $51.6(13.0)$ \\
\hline \multirow[t]{2}{*}{$\geq 10$} & 97 & 20.5 (8.6) & $19.5(4.7)$ & 18.4 (5.3) & $58.7(15.1)$ \\
\hline & & $P=0.021$ & $P=0.112$ & $P=0.005$ & $P=0.005$ \\
\hline
\end{tabular}

$G P=$ general practitioner

$S D=$ standard deviation .

${ }^{a}$ Number of respondents; responses missing for some categories.

mean attitude score was also lower for females than males but this difference was not statistically significant.

The mean overall KAP score of physicians was significantly different by speciality (Table 1). Urologists scored the highest marks followed by andrologists, psychiatrists, general surgeons, cardiologists, gynaecologists and other specialties including general practitioners $(P<0.001)$. The knowledge score of the urologists was the highest, followed by andrologists, then general surgeons, cardiologists, psychiatrists, gynaecologists, and other specialities $(P<0.001)$. The highest score for attitude was obtained by gynaecologists and the lowest by other specialities, but the difference was not significant $(P=0.087)$. The score for practice was significantly different among different specialities $(P<$ 0.001). Urologists scored the highest marks, followed by andrologists, psychia-

لبحلة الصحية لشرق المثتوسط، منظمة الصحة العلمية، البحلد العاشر، العدذان ع-0، ع • • 
trists, cardiologists, general surgeons, other specialities, and the lowest score by gynaecologists.

Table 1 also shows physicians' KAP towards erectile dysfunction in relation to their qualifications. Surprisingly, the physicians with highest qualifications, e.g. medical doctorate or equivalent, scored the lowest marks [mean knowledge score 14.5 (SD 6.3)] compared with physicians with intermediate qualifications, e.g. master's degree or equivalent, $(21.0, \mathrm{SD}=8.9)$ or general practitioners $(19.9, \mathrm{SD}=7.7)(P<$ $0.001)$. There was a similar trend on the attitude and practice sections, with significant differences among the physicians according to level of qualifications $(P=0.007$ and $P=0.008$ respectively).

The mean overall KAP score was significantly higher for physicians with 10 or more years practice than those with less than 10 years practice $(P=0.005)$ (Table $1)$. The difference between the 2 groups was significant for knowledge and practice ( $P=0.021$ and $P=0.005$ respectively) but not for attitude $(P=0.112)$.

Some examples of responses to individual questions are as follows. Question no. 10 (knowledge question) asked for the proper definition of erectile dysfunction; this was correctly answered by $66.5 \%$ of physicians. Question no.12 (attitude question) inquired about the most common etiology of erectile dysfunction; surprisingly, $52.5 \%$ of the physicians believe that it is mainly a psychogenic problem. Question no. 23 (practice question) inquired about the actions to be considered in dealing with a patient reporting a new onset of erectile dysfunction; $46.2 \%$ believed that such patients should be referred to the urologist, whereas $14.0 \%$ did not know the correct answer to this question. Question no. 26 (practice question) dealt with the therapeutic modality of choice for treating the ma- jority of cases of erectile dysfunction, and $83.9 \%$ of the physicians were able to give the correct answer.

\section{Discussion}

Erectile dysfunction is a major public health problem worldwide, but is commonly under-diagnosed $[1,2,7,13]$. In this study, we aimed to answer the main question: "Do physicians know enough about erectile dysfunction and do they have the right attitude and practice towards it?"

The study results revealed a high response rate, with 159 out of 192 meeting attendees (83\%) answering the questionnaire. The mean overall KAP score for all physicians was below $60 \%$ of the total, the known accepted standard for the evaluation of both undergraduate and postgraduate medical students. The performance of female physicians was significantly lower than the performance of male physicians, despite the assurance of the highest degree of confidentiality. Social and cultural factors may account for the significant gap in both knowledge and interest of the female physicians in this part of the world.

Approximately $80 \%$ of cases of erectile dysfunction are due to an organic cause, especially atherosclerosis of the cavernosal arteries of the penile tissue, and only $20 \%$ of the cases are due to psychiatric and psychogenic disorders [1-3]. Therefore, the clinical evaluation and treatment of erectile dysfunction should have a multidisciplinary approach. Fifty per cent (50\%) of the members of NIH Consensus Development Panel on Impotence held in 1992 were urologists, $14 \%$ were psychiatrists and 35\% were representatives of other medical specialities [1]. This misconception that erectile dysfunction is under the domain of urologists agrees with our results. Urolo-

بلملة الصحية لشرق المتو سط، منظمة الصحة العالمية، المحلد العاشر، العددان ع-0، ع • • 
gists had the highest marks in the total KAP score (73\%), followed by andrologists and psychiatrists, as compared with the rest of the specialities who scored lower. Despite the fact that $66.5 \%$ of the studied physicians were able to define erectile dysfunction correctly, $52.5 \%$ still believed that the etiology of this problem is mainly psychogenic. Furthermore, $46 \%$ of the studied physicians preferred to refer patients presenting with new onset erectile dysfunction directly to the urologist, and $60 \%$ of them ignored the importance of obtaining a detailed medical history, performing a proper physical examination or requesting the necessary investigations (such as fasting blood sugar, lipid profile, testosterone, prolactin, luteinizing hormone and follicle-stimulating hormone) [2,9].

The total KAP score of the study population was strongly affected by the level of qualifications. Unexpectedly, physicians with higher qualifications scored much lower than physicians with intermediate qualifications, and even less than general practitioners. The poor performance of highly qualified physicians may be related to an inappropriate attitude towards erectile dysfunction, whose diagnosis and management was thought to be mainly under the domain of urologists and/or psychiatrists. Physicians with higher qualifications and who are highly specialized may have little interest in updating their general medical knowledge. However, the duration of physicians' practice in years was a positive predictor of better performance. Physicians who had more than 10 years practice scored significantly higher than those with less than 10 years practice.

The increased understanding of the pathogenesis, proper evaluation and accurate diagnosis, and the available treatment options of erectile dysfunction, should stimulate health care planners to find ways of improving public awareness and physicians' up-to-date knowledge about this major medical problem.

\section{Conclusion and recommendations}

The role of physicians, especially cardiologists, is pivotal in the process of evaluation and management of erectile dysfunction. In this study of physicians who have a scientific and clinical interest in erectile dysfunction, the overall KAP scores for all physicians were below the expected standard. We recommend that:

- Undergraduate curricula and postgraduate training programmes should be modified to accommodate and emphasize up-to-date knowledge about early detection, evaluation and management of erectile dysfunction.

- The Ministry of Health, through health policy planners, universities and other medical sectors should find the proper approach and plans to improve the general public awareness regarding the importance of early diagnosis and treatment of erectile dysfunction.

\section{Acknowledgements}

We are grateful to Dr Emmanuel Larbi, Consultant Internist/Clinical Pharmacology and Professor of the Department of Internal Medicine, King Faisal University, and King Fahd Hospital of the University for his invaluable effort in reviewing this manuscript, and Mr Ramesh Kumar for his secretarial support.

بلملة الصحية لشرق المتو سط، منظمة الصحة العلمية، البحلد العاشر، العددان ع-ه، ع • • 


\section{References}

1. NIH Consensus Development Panel on Impotence. Journal of the American Medical Association, 1993, 270:83-90.

2. Miller TA. Diagnostic evaluation of erectile dysfunction. American family physician, 2000, 61(1):95-104, 109-10.

3. Feldman HA et al. Impotence and its medical and psychological correlates, results of the Massachusetts Male Aging Study. Journal of urology, 1994, 151:5461.

4. Laumann EO, Paik A, Rosen RC. Sexual dysfunction in the United States: prevalence and predictors. Journal of the American Medical Association, 1999, 281:537-44.

5. Baldwin KC, Ginsberg PC, Harkaway $\mathrm{RC}$. Underreporting of erectile dysfunction among men with unrelated urologic conditions. Abstract presented at the Annual Meeting of the American Urological Association, April 29-May 4, 2000, Atlanta, Georgia.

6. Levine LA, Kloner RA. Importance of asking questions about erectile dysfunction. American journal of cardiology, 2000, 86:1210-3.

7. El-Sakka AI, Tayeb KA. Erectile dysfunction risk factors in noninsulin dependent diabetic Saudi patients. Journal of urology, 2003, 169(3):1043-7.

8. Abolfotouh MA, Al-Helali NS. Effect of erectile dysfunction on quality of life. Eastern Mediterranean health journal, 2001, 7(3):510-8.

9. DeWire DM. Evaluation and treatment of erectile dysfunction. American family physician, 1996, 53:2101-8.
10. Pritzker MR. The penile stress test: a window to the hearts of man. Abstract presented at the 72nd Scientific Session of the American Heart Association, November 7-10, 1999, Atlanta, Georgia.

11. Billups K, Friedrich S. Assessment of fasting lipid panels and Doppler ultrasound testing in men presenting with erectile dysfunction and no other medical problems. Abstract presented at the American Urological Association, April 29May 4, 2000, Atlanta, Georgia.

12. Cheitlin MD et al. ACC/AHA expert consensus document. Use of sildenafil citrate (Viagra) in patients with cardiovascular disease. Journal of the American College of Cardiology, 1999, 33: 273-82.

13. Jackson G. Erectile dysfunction and cardiovascular disease. International journal of clinical practice, 1999, 53:363-8.

14. Jackson $G$ et al. A systematic approach to erectile dysfunction in the cardiovascular patient: a consensus statement. International journal of clinical practice, 1999, 53:445-51.

15. Jackson G. Sexual intercourse and angina pectoris. International rehabilitation medicine, 1979, 3:35-7.

16. O'Kane PD, Jackson G. Erectile dysfunction: is there silent obstructive coronary artery disease? International journal of clinical practice, 2001, 55:219-20. 